\title{
Um lugar na história: narrativas de exposições e o lugar do historiador $^{\mathrm{I}}$
}

Jheniffer Alvarenga

\section{Resumo}

Buscou-se, nesta discussão, a reunião de ideias sobre a concepção de museu e suas exposições a partir da análise de dois museus da região dos Campos Gerais (PR): o Parque Histórico de Garambeí e o Memorial da Imigração Holandesa, também conhecido como Moinho "De Immigrant". Pondera-se a ideia de museu como um ambiente em construção, como uma instituição responsável pelo diálogo entre a narrativa histórica e o público visitante. Desse modo, procura-se refletir a respeito da construção da narrativa museal, de algumas possibilidades de discurso e da influência dos profissionais responsáveis por pesar e organizar as exposições.

Palavras-chave: Museu - Historiador - Narrativa histórica.

I Artigo produzido para a disciplina de Arquivos, Museus e Patrimônio Histórico I, cursada no ano de 20I5, tendo como base visitas técnicas realizadas aos museus aqui citados, sob orientação da Prof. ${ }^{\mathrm{a}}$. Ms. Elizabeth Johansen. 


\section{Introdução}

O tema proposto é fruto de questionamentos e reflexões que procuram compreender a importância e a função de historiadores dentro de locais de guarda de memória e a importância das exposições no relacionamento com o público visitante.

Para melhor apresentar as diferenças existentes entre os discursos museais, será realizado o movimento de análise comparativa entre dois museus de temáticas semelhantes que, contemporâneos, são ao mesmo tempo produtores e reprodutores de narrativas que lhes são próprias, porém distintas.

O Moinho "De Immigrant" e o Parque Histórico de Carambeí localizam- se na região dos Campos Gerais, no estado do Paraná, respectivamente nas cidades de Castro e Carambeí. Ambos foram fundados em 200I e assemelham-se na temática abordada, referente à imigração holandesa na região, e em seus objetivos iniciais de rememoração do passado. As duas instituições resultam da iniciativa privada.

Considerando as particularidades de formação de cada ambiente, analisaremos especialmente o gênero do discurso fornecido para seus visitantes, apresentado em exposições.

\section{Museu: discurso x realidade}

Para Desvallées e Mairesse (20I3, p. 64), "o termo 'museu' tanto pode designar a instituição quanto o estabelecimento, ou o lugar geralmente concebido para realizar a seleção, o estudo e a apresentação de testemunhos materiais e imateriais do Homem e do seu meio".

Ao se pensar no termo "museu", é preciso lembrar de suas origens, mesmo que de maneira breve. Original dos gabinetes de curiosidades, o museu passou por diferentes processos de organização, sendo então institucionalizado no século XVIII. Inicialmente, adotou como finalidade conceitual a tarefa de construir e legitimar os Estados Nacionais por meio de narrativas específicas. Desde o século XIX, com o Louvre, esse ambiente esteve reservado à guarda de objetos pessoais e coleções familiares que tinham seu direito a exposição garantido unicamente devido ao valor representativo dos heróis da nação. Essa seleção do que e, consequentemente, de quem poderia ser representado, passou de certa forma a também selecionar quem poderia vê-la, não apenas por ações mandatórias, mas, sobretudo, por seu discurso, tornando o ambiente essencialmente burguês. 
A falta de representação de uma história comum e para todos fez com que esse espaço fosse constantemente questionado, levando à renovação conceitual de como se pensar um museu e sua finalidade. "Foi preciso haver uma mudança a nível mundial acerca do papel dos museus, conclamados a buscar cada vez mais a aproximação com o cidadão comum, chamando-o a participar da história de seu país." (GUEDES, 20IO, p. IIO).

Entende-se que foi a partir da década de 1970 que a noção e prática tradicional de museu passou a ser criticada e repensada por seus profissionais, que não viram na instituição a representação social exigida pelos movimentos sociais emergentes no período (DUARTE, 20I3). O movimento de contracultura iniciado na década anterior atuou em diversas frentes, especialmente pelo movimento conhecido como Maio de I968, que buscou maior representatividade e respeito pelas "minorias" 2 . Inicia-se, então, a expansão de ideias que previam a inserção de novos sujeitos na história, movimento que, tendo origens na Europa, espalhou-se pelo mundo, estando presente também no Brasil. Passa então a ser questionada a atuação social do museu, o que leva à reestruturação conceitual dessa instituição.

A partir da década de 1970 , as novas práticas desenvolvidas nos museus priorizam o respeito à diversidade cultural, a integração dos museus às diversas realidades locais e a defesa do patrimônio cultural de minorias étnicas e povos carentes. Mais do que isso, os museus modificaram a relação cotidiana entre profissionais de museus, exposições e público (SANTOS, 2004·p. 58).

Como afirma a autora, houve uma mudança - principalmente ideológica nas práticas cotidianas dos museus, que precisaram olhar e trabalhar de forma diferente seus objetos e suas coleções ao construir exposições, visando a integrar dentro de sua narrativa a pluralidade social.

Segundo Meneses (I994), os objetos dentro do museu perdem seu uso original e passam a integrar coleções. Desse modo, a visão empregada pela equipe responsável pela organização das exposições pode recriar e adotar novos significados para os objetos, respeitando ainda assim suas origens. A partir disso, é válido ressaltar a importância dos profissionais encarregados de tal função. Novos olhares adotados a respeito dos objetos podem elaborar diferentes narrativas históricas, com base na orientação conceitual e ideológica de cada instituição.

2 Gf. KRÜGER, G. Impressões de I868: contracultura e identidades. Acta Scientiarum, Maringá, v. 32, n. 2, p. I39-I45, 2010. 
Acredita-se que, para o enriquecimento da narrativa histórica proposta pelas instituições museais em conteúdo, é necessário o estudo do objeto-documento, exigindo-se, para a elaboração da narrativa proposta, a complementação dos objetos com outros documentos. Igualmente, vê-se a necessidade de integrar, dentro da pesquisa histórica, outras áreas do conhecimento como artes visuais, arquitetura, arquivologia, antropologia, sociologia, museologia, arquivística, biblioteconomia etc. Juntos, os conhecimentos possibilitam a elaboração da história-problema, com questões que colaboram para o surgimento de novos significados e novas interpretações sobre um mesmo fato. Ações como essas são expressas através das exposições, espaços repletos de significados intrínsecos e construídos, reservados para a interação entre acervo, museu e público. Porém, um aspecto específico chama atenção: as diferenças existentes na forma como cada museu se apresenta.

Uma vez que a exposição é a materialização das intenções e dos posicionamentos ideológicos de quem a produz perante a sociedade, esse espaço é, essencialmente, fruto de trabalho intelectual pensado e realizado por meio de escolha/seleção, tornando-se fundamental a abordagem lançada sobre os objetos por meio de ações conscientes e definidas conforme a realidade social em que cada profissional está inserido. Logo, atentamos para uma importante questão: as intenções de uso das peças.

O entendimento de objeto-documento ocorre principalmente pelos sentidos adotados sobre as peças que serão escolhidas, organizadas e apresentadas em forma de exposição a partir de questionamentos.

Ao se considerar o espaço das exposições como local de relacionamento entre instituição, acervo e público, vale questionar a influência e a importância da participação do responsável no tratamento das fontes no que tange às suas posições político-ideológicas. Como a exposição é produto de um trabalho e sua finalidade é representar a instituição e a transmissão de conhecimento a partir de seus documentos, percebe-se então a importância desse profissional e de suas concepções, pois suas ideias transpassarão o museu, uma vez que esse profissional não está excluído do contexto em que vive. Logo, suas ações correspondem a posicionamentos construídos a partir de sua consciência histórica ${ }^{3}$.

3 A consciência histórica é um conceito elaborado por Jörn Rüsen, que defende que o sujeito histórico ativa sua consciência histórica quando utiliza de suas memórias para elaborar respostas a obstáculos cotidianos. Cf. RÜSEN, Jörn. Razão histórica: teoria da história: os fundamentos da ciência histórica. Brasília: Editora UNB, 200I. 
Com diversas possibilidades de elaboração, o valor de origem dos objetos que farão parte da exposição não é excluído em sua totalidade, mas assume dentro de um conjunto novos significados, conforme o tratamento curatorial escolhido pelo profissional e pela instituição.

Passetti (I999, p. I69) frisa que:

O primeiro problema da escolha começa a ser resolvido quando se reconhece que decidir sobre o conteúdo do acervo, quais as diretrizes que norteiam as pesquisas e o que será exposto - e como - são resoluções que dependem de políticas: não apenas políticas administrativas, localizadas em procedimentos burocráticos que permitem o museu funcionar através da organização administrativa, financeira, científica e técnica, mas de escolhas que obedecem a posições políticas e éticas.

Essas escolhas implicam posicionar-se diante de temas muitas vezes considerados tabus sociais. A resposta do público pode ser negativa, mas isso significa que de certa maneira uma das finalidades foi atingida: o diálogo não retórico com o visitante, que instiga a pensar e questionar sobre o conteúdo exposto. Torna-se claro que, com o mesmo acervo, é possível realizar duas ou mais formas de narrar a história. Cabe então a escolha. Mas como escolher?

Organizar uma exposição não quer dizer, simplesmente, agrupar ou colocar os objetos de maneira isolada, descrever em placas explicativas sua origem, seu tamanho e a quem pertenceram, em uma perspectiva exclusivamente contemplativa. Consiste, como afirma Passetti (I999), em implicações mais profundas, sendo responsabilidade do museu realizar uma escolha clara de suas políticas de entendimento social e apontá-las por meio das exposições, que deverão assumir caráter ético.

Mas em que momento o historiador atua na instituição? No caso do Museu Paranaense ${ }^{4}$, localizado em Curitiba (PR), o diretor do museu afirma que ao se tentar integrar as minorias sociais dentro do discurso museal é preciso, no espaço, na organização e na ligação entre os objetos, formular problemas a partir de pesquisa histórica, para que se possam agregar novas informações ao conjunto exposto (informação verbal) ${ }^{5}$. Em um acervo formado especialmente por doações de famílias e empresas tra-

4 Para mais informações e detalhes, o site da instituição é http://www.museuparanaense.pr.gov.br. 5 Informação obtida em conversa informal com Renato Augusto Carneiro Júnior, diretor do Museu Paranaense. 
dicionais do estado, esse tipo de posicionamento fortalece a renovação da instituição sem a necessidade de modificar o acervo, apenas o olhar adotado sobre ele.

Desse modo, um acervo que tem características positivistas não precisa transmitir a noção tradicional da história, pois, quando visa à integração entre os conhecimentos multidisciplinares, os objetos e o público visitante, torna-se capaz de ampliar seu entendimento de história e narrativa no momento de elaborar uma exposição.

Ao se montar um circuito histórico, não é necessário retirar peças de personagens ilustres da exposição. Basta organizá-las de maneira que não sejam unicamente contemplativas, e sim inseridas em um contexto histórico com fundamentos teóricos e metodológicos, agregando conteúdo às discussões latentes na sociedade contemporânea.

Vemos que os objetos se tornam documentos a partir do olhar adotado sobre eles. O historiador é o profissional instrumentalizado para a elaboração de um discurso histórico, pois trabalha com as fontes a partir de metodologias específicas e olhares diferenciados. Contudo, ele não está sozinho. Atualmente, as instituições procuram trabalhar com a multidisciplinariedade entre conhecimento histórico e demais áreas complementares à formação de exposições.

A fim de perceber a importância do responsável pela pesquisa histórica das exposições e de compreender seu papel dentro desses espaços é que este artigo se propôs a investigar a participação de tal profissional (ou a falta dela) nos museus, por meio da observação.

Foram observados dois museus regionais. Ambos expõem a história da imigração holandesa para a formação de suas comunidades integrantes dos Campos Gerais. Com características memorialistas, as duas instituições resultam da iniciativa dos descendentes em resgatar a memória de sua origem, das famílias dos imigrantes e de seus costumes tradicionais.

\section{II.I. Centro Cultural Castrolanda (CCC)}

O Centro Cultural Castrolanda (GCG), em Castro (PR), região dos Campos Gerais, reúne atualmente duas edificações que buscam preservar a memória dos fundadores da Cooperativa Castrolanda, fundada pelos imigrantes holandeses vindos em I95I. Em comemoração aos cinquenta anos desse feito, em 200I foi inaugurado o memorial De Immigrant, um moinho de vento em tamanho real - instrumento de trabalho tipicamente holandês que, somado ao 
museu Casa do Imigrante Holandês, já existente desde I99I, forma o conjunto memorial de Castrolanda. A partir de 20I6, com a idealização e finalização da construção de um novo complexo, o conjunto memorial passou a ser denominado Centro Cultural Castrolanda.

\section{II.II. Associação Parque Histórico de Carambeí (APHC)}

Localizada na cidade de Carambeí (PR), também na região dos Campos Gerais, a Associação Parque Histórico de Carambeí (APHC) foi constituída em 200I, partindo da iniciativa privada com apoio da Lei Rouanet ${ }^{6}$. Seu objetivo é "preservar a memória dos pioneiros holandeses na região dos Campos Gerais e assim difundir a cultura dos imigrantes por meio de seu Patrimônio Material e Imaterial" (APHG, 20I6). Em extensão territorial, o parque conta com cerca de cem mil metros quadrados de terreno, o que faz dele um dos maiores museus a céu aberto do país ${ }^{7}$, representando a formação da vila holandesa de Carambeí, fundada em I9II. Analisaremos em especifico o discurso adotado dentro da Casa da Memória, localizada dentro do parque.

\section{Análise discursiva das exposições}

Inicialmente, os objetivos que movimentaram o grupo de moradores de $\mathrm{Ca}$ rambeí que construiu a APHC foi a rememoração de suas raízes a partir de objetos e histórias que os integrantes do grupo possuíam como herança de seus familiares. Atualmente, a visão adotada pela instituição é também educativa. O museu, por meio de um projeto denominado "Museu interativo", tenta se aproximar do público ao representar o cotidiano da Colônia de Carambeí do início do século XX. Atualmente, pode-se observar que a tendência em permanecer com o discurso de contemplação devido às suas raízes não ocorre na

6 Segundo o site do Ministério da Cultura (BRASIL, 20I6c), O Incentivo Fiscal (Renúncia Fiscal) é um dos mecanismos do Programa Nacional de Apoio à Cultura, instituído pela Lei Rouanet (Lei 8.3I3/I99I). É uma forma de estimular o apoio da iniciativa privada no setor cultural. O proponente apresenta uma proposta cultural ao Ministério da Cultura e, caso seja aprovada, é autorizada a captação de recursos junto às pessoas físicas pagadoras de Impostos de Renda ou empresas tributadas com base no Lucro Real para a execução do projeto.

7 Para mais informações e detalhes, o site da instituição é http://www.parquehistoricodecarambei. com.br/. 
APHC. Observa-se que as exposições do parque permitem um deslocamento da celebração histórica para a problemática histórica.

A atuação de profissionais qualificados torna-se perceptível a partir das exposições, que, ao reconhecer o contato com outros grupos étnicos que conviveram com a comunidade e a influência de outros grupos étnicos, demonstra a consciência da formação social e a não exclusividade da cultura holandesa na região. Essas afirmativas podem ser observadas na utilização de lambrequins ${ }^{8}$ em uma das casas montadas na exposição. O lambrequim comum das casas polonesas passou a ser adotado por alguns dos holandeses pela utilidade prática de tal adereço ao clima chuvoso da região, agregando informações aos conhecimentos arquitetônicos e costumes trazidos com os imigrantes e demonstrando as relações e possíveis tensões entre os diversos grupos de imigrantes que se estabeleceram na região.

Dessa forma, o contato e/ou choque cultural da região é transmitido para o público por meio de associações e explicações que podem parecer simples, mas que resultam de pesquisas ao acervo do museu. Nesse caso, a APHC é tratada como centro de pesquisa, colocando os objetos em condição de documento histórico.

Ainda sobre o Parque Histórico de Carambeí, é possível destacar um ambiente montado para a problematização da representatividade da mulher dentro da colônia a partir de vestimentas e utensílios domésticos que, organizados, permitem ao leitor questionar a imposição de papéis femininos no passado e na atualidade. A Casa Portuguesa, pertencente a uma Sinhara importante da região no período colonial, foi escolhida como espaço para tal discussão. A exposição, ainda em processo de construção, demonstra nas escolhas das peças e na organização o caráter político adotado pela instituição, voltado à problematização do papel da mulher nas dinâmicas sociais a partir de objetos que as representavam naquele momento e que, atualmente, promovem discussões e desconstruções discursivas.

A problemática histórica se encontra exposta, uma vez que pensar o feminino no século XX é uma necessidade do presente. Por discutir e trazer à tona valores que foram, no decorrer dos séculos, atribuídos às mulheres como padrões do feminino ou produtos de defesa de grupos feministas, os objetos

8 "[Arquitetura] Ornato que pende de um sólio, de um pavilhão, de uma cantoneira, etc. (Mais usado no plural); [Heráldica] Ornato pendente do elmo. (Mais usado no plural) = PAQUIFE. (LAMBREQUIM, 20I6). Segundo o monitor do parque, o uso dos lambrequins nas casas holandesas de Carambeí representava a inserção da cultura polonesa no convívio local. 
organizados levam a uma reflexão muito significativa sobre a imposição e associação da presença da mulher em ambientes exclusivos e segregacionistas, como o doméstico, ideia que é constantemente refutada na atualidade. São sentimentos e posicionamentos transpassados pelo interlocutor ao ouvinte por meio dos objetos, cujos valores simbólicos, naquele momento, problematizam a figura feminina.

No cotidiano, adotamos significados próprios aos nossos objetos e funções definidas, funções estas muitas vezes múltiplas, que representam a forma como socialmente nos relacionamos com o meio material. Dentro de uma instituição museal, o objeto pode e deve ser tratado de maneira que não respeite apenas o uso pelo qual foi fabricado, sendo também depósito de sentimentos, sonhos, medos, expectativas e lembranças das mais distintas. Cabe ao museu e aos seus profissionais definir qual será o papel desse objeto e como ele vai representar suas ideias por meio da exposição.

A estrutura do moinho é o ambiente a ser analisado, pois ele foi construído especialmente para servir como museu e representar as raízes e o passado na Holanda. Essa é uma ferramenta símbolo do trabalho, considerada a primeira peça do museu e, quiçá, o maior atrativo do Centro Cultural Castrolanda. No Museu De Immigrant - O Moinho, ao subir o primeiro lance de escadas o visitante se depara com objetos que relembram a chegada dos primeiros imigrantes holandeses no ano de I95I e como eles atravessaram o Atlântico, sofrendo as barreiras da língua, do clima e do solo. Isso por meio de roupas típicas e malas que recordam a viagem, ou seja, o processo de mudança. Os primeiros contatos e acomodações, a partir de imagens da construção dos primeiros edifícios - escola e igreja -, mostram que a problemática está ligada unicamente à vida exclusiva da colônia. O público é convidado a conhecer a história desse grupo, que se mostra linear, ou seja, com início e fim nela mesma, o que dá um caráter memorialista à exposição.

Já no segundo piso, as escadas levam ao que considero mais representativo da história contínua: uma linha do tempo que tem início na chegada à região e se encerra com os produtos e o desenvolvimento da cooperativa, convidando o visitante a subir ao terceiro piso. Estão expostos, também, alguns documentos da imigração entre Holanda e Brasil, os quais se encontram no mesmo ambiente que alguns pregos, fotografias e outros objetos, o que não permite entender de forma clara a relação ou os motivos de tal disposição entre os objetos, o contexto da exposição e a temática abordada pelo museu.

Subindo para o terceiro ambiente o visitante é convidado a assistir a um vídeo que narra o percurso da colônia holandesa e a construção de Castro- 
landa, no qual as imagens e a apresentação colocam para o público os momentos de maior importância dentro da colônia e da cooperativa, enfatizando o valor daqueles que conseguiram superar as adversidades do solo, do clima e da língua devido a sua persistência e força para alcançar a vitória, ideal coletivo que se materializa na indústria. O discurso apresentado, defendido e enfatizado no ambiente três trata-se de uma iniciativa de interação com o visitante, porém o conceito adotado é o memorialista, para o enaltecimento da cooperativa.

O museu, ao adotar esse gênero narrativo, ressalta sua opção em contar a história focada na própria empresa, retirando a profundidade e complexidade das relações produzidas por indivíduos que pensavam e se organizavam de forma singular, reflexo de tensões sociais, econômicas e religiosas, entre outros pontos.

\section{Considerações finais}

Defende-se aqui que o museu possui, como uma de suas finalidades, a produção de conhecimento, seja por meio de ações educativas, de pesquisas ou da expografia utilizada, a fim de convidar o público a interagir com a instituição. Os profissionais que trabalham para tal finalidade, em especial o historiador, permitem que o museu possa ser entendido como um local que se renova e vive em constantes transformações, até mesmo em exposições de longa duração, o que mostra que conceitualmente o museu está em contínuo movimento.

A metodologia utilizada pelo museu O Moinho revela a falta de especialistas, como museólogos e historiadores, para a elaboração científica das exposições. Isso porque seu objetivo não é educativo ou social, mas de autorrepresentação da superação da colônia, tornando a história já construída e imutável. É visto que existe uma linha de raciocínio e trabalho por trás da exposição. Contudo, a qualidade técnica museológica e historiográfica deixa a desejar. Desse modo, a falta de multiplicidade da história, na releitura dos fatos, corrobora o entendimento do senso comum de que a narrativa histórica é única e linear, rumo ao progresso. Essa circunstância acaba por empobrecer as discussões a respeito de nossa sociedade e, consequentemente, engessa um modelo social a ser seguido.

Dotado de valor simbólico, o espaço museal deve ser pensado como causador de impacto ao visitante, seja esse impacto positivo ou negativo. Esse deve ser o objetivo. É responsabilidade dos organizadores-pensadores das exposições arranjar os documentos de forma que: a) sejam visíveis as ligações e 
a comunicações entre eles, permitindo-se que sejam entendidos dentro de uma linha discursiva ou temática; b) as escolhas das peças, seus lugares, seus pares, suas influências estéticas e os dispositivos visuais atraiam o visitante; c) proporcionem questionamentos e sentimentos para o observador, a fim de instigar o visitante à divulgação do museu e possibilitar possíveis retornos. Trata-se de um ambiente educacional, transformado e transformador.

Sendo o museu qualificado como local de guarda e problematização histórica, logo ambiente de pesquisa e aprendizado, observa-se a importância da mão de obra qualificada dos responsáveis por funções estritamente intelectuais como as exposições. São espaços que dependem de pesquisa histórica e documental baseada na problematização, para a qual o Bacharelado em História serviria de formação inicial.

Consideramos que é inegável a existência das dificuldades em relação aos conteúdos e à qualidade dos objetos acumulados. Porém, a diferença está na intencionalidade de cada instituição em transmitir sua releitura da história. Ambas as instituições em questão derivam da iniciativa privada, recebendo financiamento de grandes empresas da região e tendo sido construídas com o apoio das comunidades e sem restrição financeira considerável, o que torna a utilização de profissionais especializados questão de interesse e escolha.

Contudo, nota-se que a APHC vem se renovando aos poucos, transformando o discurso adotado incialmente, que de maneira geral era também memorialista e engessado, construindo exposições que instigam o visitante, levando-o a interagir e aprender com a história da imigração na região. Mas ressalta-se que isso está em processo, devido aos profissionais especializados que lá atuam.

A falta de formação profissional específica da área de pesquisa documental gera, em muitos casos, o que apontamos no museu $\mathrm{O}$ Moinho: a não contextualização do objeto com o social. O discurso baseado na meritocracia, sobre um grupo em cuja trajetória busca-se, por meio dos objetos, o sentimento de realização e vitória toma espaço e não permite abertura para construções históricas, para que questões atuais fundamentem-se no passado. Trata-se de um museu que se encerra em si. Uma vez introduzida essa noção aos visitantes, defendemos que a possibilidade do retorno ao local é menor. Há interesse em conhecer a mesma história diversas vezes?

Atendendo às necessidades sociais atuais, observa-se que há uma gama de possibilidades e temáticas a serem trabalhadas, passíveis de renovação conforme as durações de cada exposição - curta, média ou longa.

Assim, acredita-se que o discurso histórico é dotado de intenções por parte de quem fala, intenções estas que representam o uso do poder que 
é concedido a determinado indivíduo. Enquanto é o Estado que fala oficialmente com o público, este detém o poder para escolher as palavras, as histórias e os resultados que melhor lhe caibam dentro dos usos sociais. Porém, no momento em que se atribui ao museu independência, o direito de escolher por quem e para quem irá falar, a situação se modifica, pois, o poder sobre o discurso de sua instituição lhe pertence. Logo, o museu atribuirá a suas exposições as intenções que melhor lhe representem. Está em suas mãos escolher entre as diferentes possibilidades historiográficas que a teoria permite. Cabe a ele saber utilizar das armas que detém: seus documentos.

Após essa análise e comparação, podemos contextualizar não apenas a ideia de museu e as suas diferentes funções, mas, em conjunto, as percepções práticas da atuação e importância das exposições enquanto locais onde as instituições conversam com seu público, transmitindo politicamente seu lugar no discurso histórico e a importância dos profissionais que nelas atuam.

Visitar uma instituição museal consistiria, então, apenas em conhecer peças e histórias? Uma vez visitada, os conhecimentos sobre ela ou sobre o assunto são encerrados e seu conteúdo, finalizado?

Com esses questionamentos, finalizo o presente trabalho com uma única segurança: o museu não se encerra; renova-se.

\section{Referências}

BRASIL. Arquivos do Blog. Portal do Instituto Brasileiro de Museus. 20I6a. Disponível em: 〈https://goo.gl/pf48o3>. Acesso em: 2I nov. 2016.

BRASIL. Instituto Brasileiro de Museus. 20I6b. Disponível em: <http://museus.gov. br>. Acesso em: 2I nov. 2016.

BRASIL. Ministério da Cultura. Projetos incentivados. Portal do Ministério da Cultura. 20I6c. Disponível em: 〈https://goo.gl/nikNgo〉. Acesso em: 23 maio 2016.

DESVALÉES, A.; MAIRESSE, F. Conceitos-chave de museologia. São Paulo: Armand Colin, 20I3. IOO p.

GUEDES, A. G. A formação da coleção de brinquedos do Museu Histórico Nacional: memórias afetivas, história e histórias. Anais do Museu de História Nacional, Rio de Janeiro, v. 42. p. IO7- I23, 2010.

LAMBREQUIM. Portal Priberam - Dicionário. Dicionário Priberam da Língua Portuguesa [em linha], 2008-20I3. Disponível em: <https://www.priberam.pt/ dlpo/lambrequim>. Acesso em: 22 abr. 2017. 
MENESES, U. T. B. Do teatro da memória ao laboratório da História: a exposição museológica e o conhecimento histórico. Anais do Museu Paulista. São Paulo, v. 2, p. 9-42, jan./dez. I994.

PASSETTI, D. V. Museologia, ética e estética. In: ENGONTRO REGIONAL, MUSEOLOGIA, FILOSOFIA E IDENTIDADE DA AMÉRICA LATINA E NO CARIBE, 8., I999, Coro (Venezuela). Anais... Coro (Venezuela): ICOFOM LAM, I999. p. I68-I72.

SANTOS, M. S. Museus brasileiros e política cultural. Revista Brasileira de Ciências Sociais, São Paulo, v. I9, n. 55, p. 53-72, 2004.

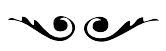

Jheniffer Alvarenga é graduanda em História pela Universidade Estadual de Ponta Grossa. jhenialvarenga@gmail.com 